\title{
Problems of distance learning for students with disabilities in a pandemic
}

\author{
O.A. Denisova ${ }^{1 *}$, O.L. Lekhanova ${ }^{2}$, and T.V. Gudina ${ }^{3}$ \\ ${ }^{1}$ Cherepovets State University, Cherepovets, Russia \\ ${ }^{2}$ Cherepovets State University, Cherepovets, Russia \\ ${ }^{3}$ Cherepovets State University, Cherepovets, Russia
}

\begin{abstract}
The article considers the problems of distance learning for students with disabilities during a pandemic. The survey was organized and conducted to reveal the attitude to distance learning and determine the challenges encountered. During the survey, the disabled students' satisfaction with distance learning during the pandemic was assessed, the advantages and difficulties they faced during the period of quarantine study were identified. The survey involved the students with visual, hearing and movement impairments, as well as the students with limited mobility and the disabled students with systemic diseases. All the students study at Russian universities located on the territory of 8 constituent entities of the North-West Federal District (Arkhangelsk region, Vologda region, Kaliningrad region, Murmansk region, Novgorod region, Pskov region, Republic of Karelia, Republic of Komi). The total of 230 respondents took part in the survey. The article analyzes the disabled students' response to the quarantine caused by the pandemic, and also describes the specificity and severity of the problems depending on the kind of the students' health limitations. The analysis of the responses allowed us to conclude that the problems of the socio-psychological (low self-motivation and selforganization, fatigue, low mood, lack of live communication) and technical (the problems with the Internet communication and distance learning platforms) come to the fore. The identified difficulties allowed the authors to make a list of recommendations to be used when organizing distance learning for students with disabilities. The proposed recommendations imply the application of the practice of permanent psychologicalpedagogical and socio-psychological support for the education of students with disabilities.
\end{abstract}

\section{A problem statement}

Worldwide, the pandemic period and forced self-isolation have entailed new social and psychological phenomena, the advantages and difficulties unusual for people living out of quarantine. Some losses and gains were recorded in education [1]. In many countries of the world that switched to distance learning during the pandemic, the researchers started the discussion on the following issues: the way the level of education influences human

*Corresponding author: ipcs-profped@yandex.ru 
behavior in self-isolation [1], special ("pajamas") behavior in a quarantine [2]; difference between the behavior of students, as representatives of one generation, from the behavior of their parents [3], the needs of young people forced to study remotely [4].

Students with disabilities are among those who, even under usual conditions of a university study, face great obstacles and barriers, since the support and learning tools they need are not always available [5], [6]. The existing achievements in digital technologies aimed at meeting specific needs of disabled students, allow us to define it as one of the central issues of modern social, humanitarian and pedagogical knowledge [7], [8], [9]. Taking into account the current situation, the issue of difficulties experienced by students with disabilities in distance and online education during a pandemic acquires a new research and social meaning. It is important to assess the attitude of disabled students to distance learning during the pandemic and their personal gains and losses are not studied. The absence of such data does not allow developing reasonable recommendations on distance learning for students with disabilities, though it infringes on their rights equal opportunities in education reducing the chance for positive socialization and successful integration into society. The contradiction between the need to identify the problems of distance learning for people with disabilities during a pandemic and the lack of generalized and systematized recommendations that take into account these problems, determined the relevance of the study. The authors' experience in organizing and implementing the work of the Center for Supporting Students with Disabilities at the University [10], [11], [12], [13], [14] made it possible to take into account the existing developments of the federal network of Resource educational and methodological centers for teaching people with disabilities in the Russian Federation universities when conducting research and developing recommendations.

\subsection{The objective of the work}

The analysis of the achievements in the field of distance learning for disabled people during the pandemic allows us to distinguish two groups of data. The first group is related to the assessment of the general situation of distance learning during the pandemic. In this group the journalists' publications, experts' speeches, the reports of various organizations prevail. The second data group of concerns the analysis of the advances in distance learning for people with disabilities. These works deal with the description of the specifics of students with disabilities, their psycho-physiological and socio-psychological traits.

Let's analyze the first group of the studies on the impact of the pandemic on education.

The report of the International Labor Organization (ILO) "Youth and the COVID-19 pandemic" noted that more than $65 \%$ of the young people were not satisfied with the quality of education during the quarantine period. According to the ILO, almost half of the young people may experience feelings of anxiety or depression, and another $17 \%$ indicate their depression. As a separate problem, the experts consider the "digital divide of territories", in which a particularly difficult situation for distance learning develops in lowincome countries, where the Internet is less accessible, there is a lack of equipment and housing conditions. ILO experts note that the results obtained indicate the threat of reducing the production potential of an entire generation [1].

In this respect, it is appropriate to mention the results of the study conducted by the Higher School of Economics, according to which the level of digital skills in Russia is noticeably lower compared to the indicators of the most European countries [15]. Among the country's adult population, communication skills are the most widespread (using social networks, making phone or video calls over the Internet). Slightly less often than the average for the EU countries, the Russian citizens use the Internet to upload their own content (26 versus 30\%) and obtain information from the websites of state / municipal 
authorities (39 versus 44\%). In general, Russians are much less likely than the residents of European countries to use computers and other electronic devices; less often they use email, text editors, spreadsheets, presentations, and programming languages.

The analysis of the educational requests of the users of three large platform integrators Coursera, Timepad and Edumarket, made by N. Shirkova and I. Korshunov (2020) during the pandemic, is of great interest. The analysis carried out by the researchers showed that in self-isolation, Russians realized the need to develop their hobbies, learn foreign languages and improve relationships with children. A significant trend is associated with an increase in the total number of educational courses (by 2.5 times) with a general decrease in demand for professional programs. The following courses were in high demand during this period: IT courses (the courses on maintaining blogs and developing sites were the priority), medical courses, courses on learning foreign languages, courses on business development and new product promotion forms, as well as courses that form supra-professional skills (stress resistance, leadership qualities). The demand for courses in social communication and communication management technologies has dropped significantly. The researchers note that the main interest in online courses was in the arts and crafts, cooking, fitness, sports as hobbies. According to the researchers, the identified tendencies towards thematic requests of integrator platforms users are associated with the desire to usefully spend free time that suddenly appeared, as well as to reduce the impact of a stressful situation on their lives [2].

The demand for flexible competencies is also evidenced by the data of the survey carried out by V. Kasamara and I. Gruzdev. In the students' survey implemented in two periods (from March 24 to April 1 and from May 24 to June 1, 2020), V. Kasamara and I. Gruzdev made an attempt to assess the problems and attitudes of the students during the transition to distance learning in the pandemic. The results showed that the adult students (undergraduates) coped with the transition to the online format most easily but for the firstyear students it was quite challenging. According to the researchers, the most frequent problems faced by the students during the transition to distant learning in the quarantine period were technical problems $(52 \%)$, lack of social life, communication $(43 \%)$, difficulties in organizing their own curriculum and workplace $(39 \%)$ and lack of etiquette for online communication (31\%). The survey also revealed positive trends that formed in April and May 2020: many students began to get tired of studying less, about half of the respondents began to sleep longer, $34 \%$ began to attend classes more often, $32 \%$ liked online learning more than traditional classes. In general, the authors emphasize that distance learning requires students to have a developed skill of self-organization. According to V. Kasamara, "in any case, changes will take place in the post-COVID era, and the skill of self-organization, internal high motivation will come to the fore. From the point of view of changes in the labor market, such people will be in great demand " [3]. The authors also believe that the experience of the transition of Russian universities to a distant mode of work will have a serious impact on the higher education development in the country and on the more active inclusion of online formats into the educational process.

The survey conducted by the All-Russian public organization "Russian Professors' Assembly", made it possible to summarize the opinion of Russian universities students on the work of universities in a forced distance format. So, despite the fact that distance learning is one of the most popular ideas for university education, the majority of the students surveyed said that until March 2020 they had no personal experience of getting education in a distance format $(67.6 \%)$. The data analysis obtained in the survey allows them to rank and determine that emotional problems are in the first place: negative emotions, fear for the prospects of their education, confusion, uncertainty $(77 \%)$. The students note a negative impact on motivation to study (57\%), a decrease in work efficiency $(40 \%)$, a decrease in creativity (32\%), technical problems $(24 \%)$, problems of self- 
organization and shortcomings of the university work (17\%). As negative factors of distance learning during the period of self-isolation, students single out: the lack of opportunities to participate in a full-fledged student life and communication (19\%), the lack of direct communication with teachers $(18 \%)$, an increase in the proportion of independent work and the lack of full-fledged laboratory studies $(17 \%)$. To the positive factors they referred: saving time on the way to the university $(21 \%)$, the possibility of learning in a comfortable environment (18\%), the ability to master new skills and resources $(10-13 \%)$. The conclusions drawn from the results of the survey indicate that the main difficulties in organizing distance study can be summarized in two groups. The first is technical problems and the lack of the necessary equipment. The second is personal problems (motivation, selforganization, self-discipline). The information obtained allowed the authors of the survey to determine that distance learning is not suitable for everyone, not all students can organize their time and space for distance learning [4].

Russian medical research also testifies to the special problems of the students during the quarantine period. The survey of the National Medical Research Center (NMRC) of Children's Health of the Ministry of Healthcare of the Russian Federation, in which 29,779 schoolchildren from 5 to 11 grades from 79 regions of the Russian Federation took part, showed that $83.8 \%$ of students had unfavorable mental reactions at the border level. $42.2 \%$ of the respondents demonstrated depression, $41.6 \%$ - asthenia, 37.2\% - obsessive-phobic states, $29.2 \%$ - hyperkinetic reactions, $26.8 \%$ - headache syndrome, $55.8 \%$ - sleep disorders. Almost half of the respondents indicated that they had to increase the time spent on working at the computer, almost $60 \%$ spent more time on of homework. In general, the results of the survey prove that digitalization has its own risks and threats [16].

The second group of the researches are aimed at the description of the specifics and special educational needs of the students with disabilities, including the needs met by distance learning technologies. Conventionally, it is possible to single out an informational, psychological and pedagogical approach to the problem.

An informational approach is associated with the development and assessment of digital tools to meet special needs of people with disabilities. The relevance of such development is currently a priority both in the practice of the countries of Eastern and Western Europe, the USA and Japan, and in our country. A special place in the research agenda is occupied by the issues of universal design, accessibility of educational content, assessment of elearning tools [7], [8]. Accessibility of digital services for disabled people is considered separately. This aspect of the problem has a pronounced applied value and is one of the significant components of the development of society and the digitalization of the economy [9], [17]. An accessible digital environment and digital tolerance are aimed at ensuring equal access for people with disabilities to digital technologies, artificial intelligence services, neural networks, which provides the maximum integration of people with disabilities into all spheres of public life and their maximum participation in social processes and phenomena. Within the framework of the information approach, the typology and content of digital means to meet the special needs of people with disabilities are determined, special tools, services and technologies are being developed to support various aspects of disabled people's life. One of the applied aspects of the research is related to the study and development of the tools for providing people with disabilities with access to information, global Internet networks, and the educational process on an equal basis with others. In this context, the research determining the requirements for clarity, reliability, and adaptation of sites to the special needs of users is significant.

A.A. Margolis, naming the drivers that stimulate the development of blended learning, places particular emphasis on such reasons as the desire to create a personalized instruction model; increasing learning motivation and student engagement in learning (in comparison with traditional learning); the need to increase study time and expand the list of available 
learning resources; interest of stakeholders in bridging the digital gap between students with different access to information resources and their "digital" competence, as well as a potential increase in the availability of the best teachers (the possibility of using video lessons conducted with their participation) [18].

In the pedagogical aspect, recognizing the inevitability and promising potential of digitalization, P.N.Bilenko, V.I. Blinov, M.V.Dulinov, E.Yu. Yesenina, A.M. Kondakov, I.S., considering the risks of digitalization in vocational education and training, highlight the possible losses that the digitalization of education can lead to. Among the most significant ones the authors distinguish:

- the risk of deformation of thinking, worldview, system of value orientations;

- the risk of excessive "digital optimism" and "humanitarian pessimism" with exaggeration of the possibilities of digitalization and underestimation of the significance of the human factor;

- the risk of substituting digitalization of education for digitization, in which the teacher removes himself from the educational process, reducing his involvement and supporting the dialogue "student - computer";

- the risk of digital tools developers' dictatorship with the loss of significant pedagogical goals;

- ethical risks of digitalization of the educational process;

- management risks associated with the digitalization of education in the aspect of solving utilitarian tasks, including the reduction in the cost of the educational process, its simplification and increase in its controllability [19].

The pedagogical approach is focused on the issues of distance education for disabled. The key research areas in this case are the development of methods and technologies for educational inclusion, technologies for supporting the education of disabled people. Considering inclusive education as a specific phenomenon, it is necessary to emphasize the need to form an inclusive culture in education as a culture of attitudes towards disability among all participants in educational process. Special attention is paid to the creation of special conditions for the education of disabled people and their integration into society. So, Odintsova M.A., Kuzmina E.I., Aleksandrova L.A., Lazareva V.M. believe that the proactive model of disability, aimed at the activity of the students, can act as a basis for psychological and pedagogical support of distance learning for students with disabilities at a university. In this case, psychological and pedagogical support of students with disabilities includes various forms of assistance (pedagogical, social, psychological support, self-support) aimed at enriching the psychological and pedagogical conditions of the educational environment. According to the researchers, the means of implementing a proactive model of support can be an accessible educational environment, the use of distance technologies, special support and self-support groups. The system of psychological and pedagogical support of students with disabilities, according to the authors, can be built on the basis of "understanding relationships". Such relationships presuppose barrier-free understanding, overcoming stereotypes of understanding disability, eliminating misinterpretations of the picture of the world of people with disabilities, and fostering ownership and involvement in the experience of disability. According to the authors, distance learning students (both with disabilities and normotypical fellow students) to a greater extent satisfy the need to maintain their external social status, in the implementation of creative activity. They also feel the usefulness and importance of their activities. The studies have also demonstrated a higher level of psychological well-being, the advantage of constructive coping strategies over non-constructive ones both of students with disabilities and of healthy peers in the inclusive distance learning environment. At the same time, the authors note that students with disabilities do not sufficiently recognize their value as a person, are less confident in themselves and in their capabilities, often inadequately assess 
the opinions of others about themselves, and misinterpret the reactions of others about themselves, which, according to the authors, testifies about the insufficient level of selfacceptance [20].

In the study conducted by Denisova O.A. and Lekhanova O.L. an attempt was made to describe the signs of digital tolerance of educational content for the disabled people. The paper describes the requirements for educational content, the mode of working with the material, taking into account the main difficulties of students [10].

The psychological approach is associated with the analysis of the behavior and behavioral patterns of students with disabilities. So, Kasatkina O.V. analyzed the features of independent work of psychology students at the faculty of distance learning. The author identified the main difficulties noted by students when studying at the Faculty of Distance Learning: self-regulation and self-organization, time planning. It was revealed that at distance learning, students do not have enough experience in the independent organization of time and control by teachers [21].

The research by Aismontas B.B., Akther Md. Uddin, implemented at the Faculty of Distance Learning, showed that the problem of students' readiness for distance education should be related to self-development, self-education, self-actualization, self-regulation in the educational process, as well as to motivation for professional development at a student age. It is the degree of development of these characteristics that distinguishes distance learning students from full-time students. At the same time, the former have indicators of self-actualization higher on the 12th scale. They also believe that the most important events in their life were the results of their own actions, that they can control them and, therefore, take responsibility for their life as a whole [22].

In general, the analysis of the problem makes it possible to determine that the difficulties experienced by students with disabilities during distance learning are associated with the identification of both general and specific patterns associated with the lack of formed cognitive and coping strategies for responding to stress and frustration.

\section{Materials and the results of the research}

To identify the attitude of students with disabilities to distance learning and determine existing difficulties, a survey was organized and conducted. During the survey, the disabled students' degree of satisfaction with distance learning during the pandemic was assessed, the advantages and challenges they faced during the quarantine study period were named.

The survey involved students with visual, hearing and movement impairments, as well as the students with limited mobility and general diseases. All students study at Russian universities located on the territory of 8 constituent entities of the North-West Federal District (Arkhangelsk region, Vologda region, Kaliningrad region, Murmansk region, Novgorod region, Pskov region, Republic of Karelia, Republic of Komi). A total of 230 respondents took part in the survey.

The analysis of the health status of the students who took part in the survey showed that the largest share fell on students with disabilities due to a general disease $(32 \%)$ and with disorders of the musculoskeletal system (32\%). $13 \%$ of the students did not indicate the nosology of their impairment, $12 \%$ are visually impaired (visually impaired), $6 \%$ are hearing impaired, $4 \%$ are wheelchair users, $1 \%$ are blind students.

Overall satisfaction with distance learning was $62 \% .6 \%$ of the students with disabilities are completely dissatisfied, $32 \%$ are partially satisfied. The least degree of satisfaction was demonstrated by the students with hearing impairments and disorders of the musculoskeletal system. The largest group is the students with visual impairments. The students with limited mobility who use wheelchairs, were satisfied with distance learning. 
The analysis of the problems experienced by students in the process of distance learning during the pandemic showed that the students put the increased number of tasks and loads in the first place among the other problems. Difficulties in self-organization, time planning, management of the mode of independent work are also noted by $84 \%$ of the respondents and are most pronounced among the students with disabilities due to a general disease. In second place are the difficulties associated with a lack of communication. They were mentioned by $49 \%$ of the respondents. This problem is most relevant for the students with hearing impairments. In third place are technical problems, which were indicated by $48 \%$ of the respondents. There was no certainty in terms of the dependence of technical problems on the nosology of the disorder: the respondents showed similar results.

The students with disabilities attributed the advantages of distance learning to the absence of the need to get to the place of study. This factor is significant for $44 \%$ of the respondents. It is most important for students with visual and musculoskeletal disorders. Also, among the advantages, the students point to the opportunity to follow the timetable, to rest on time ( $41 \%$ of respondents) and receive more individual consultations (12\%). Recreation is most important for the students with a general medical disability.

Thus, the data were obtained indicating that the forced massive transition to distance learning, which was imposed as the prevention of the new coronavirus infection spread, was not painless for Russian students with disabilities. In general, in our opinion, among the most significant risks of digitalization in terms of ensuring the accessibility and quality of education for students with disabilities are:

- increasing the frustration load on students with disabilities and all participants in distance learning relationships;

- a significant dependence of the results of distance learning on the technical component and the availability of digital infrastructure for students (including the compatibility of platforms and distance learning services with specialized software);

- extreme variability of digital competencies of the participants in the educational process and their dependence on previous unmanaged digital experience;

- loss or significant decrease in the socio-humanitarian and personal development goals of education;

- the predominance of the visual range during distance learning, leading to the loss of the general semantic context of learning;

- a significant reduction in the socializing and rehabilitative impact of education on the life of the students with disabilities;

- the impossibility of full-fledged high-quality individualization of the educational process in the "teacher - student" dyad;

- the loss of full-fledged communication in the systems "student - student", "teacher student", "teacher - teacher";

- an increase in requirements for self-organization and self-control, that have a different degree of development.

\section{Conclusions}

The identified difficulties made it possible to conclude that the available information about the specifics of distance learning for disabled people during a pandemic should be taken into account in order to build social forecasts regarding the strategies of the behavior of an individual, social groups and communities in the context of a decrease in the number of choices and restrictions on the life environment. To eliminate the negative consequences and losses of the period of "quarantine" distance learning, it is necessary to take large-scale and targeted measures designed to ensure the availability and quality of higher education for students in general and for students with disabilities in particular. Significant measures 
should include not only the provision of the technical access to free and unimpeded use of digital services and tools by students and teachers, but also socio-psychological and psychological-pedagogical measures related to the support of distance learning for people with disabilities and support of all participants in inclusive educational relationships. Considering the prevalence of the frustration impact of distance learning on students (both norm typical and those with disabilities), it is necessary to introduce systematic work on psychological support for participants in digital educational relationships.

It is necessary to specially prepare students with disabilities for the effective use of the resources of the digital educational environment, provide tutor support and technical assistance. Teachers also need to develop new competencies to meet the special educational needs of students with disabilities in the digital educational process.

\section{References}

1. International Labour Organization (ILO) (2020.08.11) Youth and COVID-19: impacts on jobs, education, rights and mental well-being, access mode: https://www.ilo.org/wcmsp5/groups/public/--ed_emp/documents/publication/wcms_753026.pdf

2. The adults were passionate about developing soft skills while online, access mode: https://ioe.hse.ru/news/377863525.html

3. Stranger Things: How did the students survive COVID-19? Dialogue on equal terms with Valeria Kasamara and Ivan Gruzdev, access mode: https://youtu.be/NZHI9i9bLEk

4. Help based on the results of a survey of students of Russian universities about working remotely during the forced transition to distance learning in March - June 2020, access mode: http://profsobranie.ru/201

5. Convention on the Rights of Persons with Disabilities, access mode: https://treaties.un.org/Pages/ViewDetails.aspx?src=TREATY\&mtdsg_no=IV$15 \&$ chapter $=4 \&$ clang $=$ en

6. Optional Protocol to the Convention on the Rights of Persons with Disabilities, access mode: https://treaties.un.org/Pages/ViewDetails.aspx?src=TREATY\&mtdsg_no=IV$15 \mathrm{a} \&$ chapter $=4 \&$ clang $=$ en

7. A.A. Margolis, V.V. Rubtsov, S.V. Panyukova, V.S. Sergeeva, Concept for the formation and distribution of digital content for higher inclusive education, 23 (2), 102-110 (2018)

8. S.V. Panyukova, V.S. Sergeeva, Organizational and methodological support of distance learning for students with disabilities, 11 (3), 72-83 (2019)

9. A.Yu. Shemanov, Digital technologies in the context of inclusion, 5 (3), 66-74 (2016)

10. O.A. Denisova, O.L. Lekhanova, Digital Tolerance of the Information Environment: Means of Support during a Pandemic, 67 (4), 130-133 (2020)

11. O.A. Denisova, O.L. Lekhanova, Accompanying students with disabilities in the context of inclusive higher education, 6, 202-211 (2018)

12. O.A. Denisova, O.L. Lekhanova, Special conditions for obtaining education by persons with disabilities and disabilities at the university, 10, 26 (2014)

13. O.A. Denisova, O.L. Lekhanova, On Capabilities of People with Health Limitations in Terms of Industrial Business IOP Conference Series: Materials Science and Engineering, 718 (1), 012022 (2020) 
14. O.A. Denisova, T.V. Gudina, O.L. Lekhanova, I.A. Bukina, L.A. Antonova, The role of regional higher education institutions in creating conditions for people with disabilities in inclusive educational environment of the Russian FederationIndian Journal of Science and Technology, 9 (37),102171 (2016)

15. Level of digital skills in Russia and EU countrie, access mode: https://issek.hse.ru/news/377859466.html?utm_source=issek_newsletter\&utm_mediu $\mathrm{m}=$ email\&utm_campaign=issek_nti_172

16. Research: self-isolation mode caused depression in more than a third of schoolchildren, access mode: https://tass.ru/obschestvo/9448809

17. L.S. Podymova, Tolerance to uncertainty as a factor of psychological stability of an individual in a digital educational environment, 331-337 (2018)

18. A.A. Margolis, What does blended learning mix?, 23 (3), 5-19 (2018)

19. P.N. Bilenko, V.I. Blinov, M.V. Dulinov, E.Yu. Yesenina, A.M. Kondakov, I.S. Sergeev, Didactic concept of digital vocational education and training, p. 98 (Moscow, 2020)

20. M.A. Odintsova, E.I. Kuzmina, L.A. Aleksandrova, V.M. Lazareva, Psychological and pedagogical support for students with disabilities in inclusive educational environment of university, 11 (3), 114-127 (2019)

21. O.V. Kasatkina, The experience of researching the independent work of students of the Faculty of Distance Learning, MSUPE, 14 (5), 14-19 (2009)

22. B.B. Aismontas, Md. Uddin Akther, Comparative analysis of personality characteristics of full-time and distance learning students (on the example of psychology students), access mode: http://psyedu.ru/journal/2013/4/Aismontas_Ahter.phtml 